\title{
Responsabilidade social empresarial e sustentabilidade organizacional: a hierarquização de caminhos estratégicos para o desenvolvimento sustentável
}

\author{
Corporate responsibility and organizational sustainability: the hierarchy \\ of strategic roads for sustainable development
}

\author{
Luciano Munck ${ }^{[a]}$, Rafael Borim de Souza ${ }^{[b]}$
}

[a] Doutor em Administração, professor da Universidade Estadual de Londrina (UEL) e da Pontifícia Universidade Católica do Paraná (PUCPR), Londrina, PR - Brasil, e-mail: munck@uel.br

[b] Mestre em Administração pelo Programa de Pós-Graduação em Administração da Universidade Estadual de Maringá (UEM) em consórcio com a Universidade Estadual de Londrina, Londrina, PR, Brasil - e-mail: rafaborim@yahoo.com

\section{Resumo}

O raciocínio que guiou a elaboração deste estudo considerou a responsabilidade social empresarial e a sustentabilidade organizacional como dois caminhos estratégicos possíveis de serem adotados pelas organizações em prol de ofertarem contribuições para o alcance de um desenvolvimento sustentável. Para tanto foi realizada uma pesquisa básica, qualitativa, exploratória e bibliográfica. Ao fim do artigo considerou-se que a maturidade e a ramificação da responsabilidade social empresarial podem ser observadas na sustentabilidade organizacional, uma vez que a primeira constitui um caminho organizacional estratégico inicial e a segunda um caminho organizacional estratégico avançado, ambos interessados em conceder representatividade para as organizações na busca por um desenvolvimento sustentável.

Palavras-chave: Responsabilidade social empresarial. Sustentabilidade organizacional. Desenvolvimento sustentável. Estratégia organizacional.

\begin{abstract}
The idea that has guided the elaboration of this study has admitted the corporate responsibility and the organizational sustainability as two possible strategic roads of being incorporated by the organizations so that they can contribute
\end{abstract}


in the climbing for reaching a sustainable development. It has been realized a basic, qualitative, exploratory and bibliographical research. In the end of the article it is argued that the corporate responsibility maturity and ramifications are found in the organizational sustainability, once that the first one is accepted a beginner strategic road and the second one is observed as an advanced strategic road, both interested in provide the organizations with representativeness in the search for a sustainable development.

Keywords: Corporate responsibility. Organizational sustainability. Sustainable development. Organizational strategy.

\section{Introdução}

Como ressaltou Leff (1993), a preocupação de se compreender e de se solucionar os problemas ambientais transformou-se em um conteúdo permanente em diversas discussões sociopolíticas e, também, em um objetivo responsável por conciliar diferentes interesses a fim de que, por meio de discussões de tópicos vinculados ao que se conhece por desenvolvimento sustentável, sociedades sustentáveis possam ser constituídas.

O Planeta é constituído de várias sociedades e cada sociedade é dependente da ação de inúmeras personagens sociais, logo, a busca por um desenvolvimento sustentável é fator resultante de ações realizadas em níveis micro e macrossociais. Os escopos de análise que buscam contemplar se o que está sendo promovido pelas sociedades contemporâneas realmente pode ser caracterizado como um desenvolvimento sustentável têm se tornado cada vez menores, uma vez que, para muitas ciências, já é reconhecida a necessidade se investigar as raízes das principais questões que confluem na crise ambiental.

Cada uma dessas questões está vinculada a alguns atores sociais específicos, os quais, muitas vezes, apresentam a potencialidade de gerar mais de um problema ambiental e, também, de conceder respostas a inúmeras patologias sociais inibidoras do desenvolvimento sustentável. Dentre esses atores sociais cede-se um destaque, para o contexto de análise deste artigo, para as organizações. Elas, assim como os demais elementos componentes de uma sociedade, já começam a percorrer caminhos que as deem uma representatividade considerável nos processos incumbidos de validar a conquista de um desenvolvimento sustentável.

Embora esse comportamento organizacional de aderir a movimentos intra e interorganizacionais vinculados ao desenvolvimento sustentável seja merecedor de críticas e de análises que intentem averiguar os reais interesses que levam as empresas a participarem dessa mobilidade social, é necessário reconhecer que, apesar de muitos questionamentos e em meio a inúmeras desconfianças, algo já tem sido feito pelas organizações. Tais ações organizacionais procuram estarimbricadas nas respectivas estratégias que regem o comportamento socioeconômico dessas empresas, bem por isso, admoesta-se que, em face do desafio de tornarem-se agentes sociais efetivamente representativos na busca por um desenvolvimento sustentável, as organizações têm aprimorado suas práticas de gestão em caminhos estratégicos que as auxiliem a oferecer respostas a tais demandas.

Alguns desses caminhos estratégicos são muito bem disseminados no ambiente empresarial, sendo eles a filantropia, a cidadania corporativa, a responsabilidade social empresarial e a sustentabilidade organizacional. A filantropia desenvolve-se por meio de atitudes e ações individuais de empresários, e é, portanto, diferente da responsabilidade social empresarial que tem a ver com a consciência social e o dever cívico (CAMPANHOL; BREDA, 2005). A cidadania corporativa diz respeito ao relacionamento entre as empresas e a sociedade, ao pressupor as empresas como indivíduos, pois, apesar de serem formadas por conjuntos de pessoas, elas agem individualmente em relação aos seus direitos e responsabilidades sociais (MCINTOSH et al., 2001).

É possível observar que a filantropia é algo que antecede a responsabilidade social empresarial e que a cidadania corporativa constitui um fenômeno inserido nela. Por essa constatação, desenvolveu-se este presente artigo com o objetivo de hierarquizar teoricamente, junto aos princípios de discussões relacionados, a responsabilidade social empresarial e a sustentabilidade organizacional, os caminhos estratégicos que qualificam as organizações como atores sociais coerentes em atitudes de gestão contributivas para o desenvolvimento sustentável. 


\section{Metodologia}

Conforme indicado na teorização metodológica proposta por Martins e Theóphilo (2007), este artigo desenvolveu-se por uma pesquisa de natureza básica, com o problema abordado de maneira qualitativa, com os objetivos analisados do ponto de vista exploratório e com procedimentos técnicos que envolveram um extenso levantamento bibliográfico. Foi elaborado um levantamento teóricometodológico sobre estratégias organizacionais e a visão baseada em recursos, sobre a responsabilidade social empresarial, sobre a diferença entre desenvolvimento sustentável e sustentabilidade, sobre vertentes analíticas da sustentabilidade e sobre a sustentabilidade organizacional. O contexto deste estudo confluiu na criação de uma análise que possibilitou hierarquizar a responsabilidade social empresarial e a sustentabilidade organizacional como caminhos estratégicos que contribuem para o alcance de um desenvolvimento sustentável. No Quadro 1 são elencados os principais temas tratados no artigo, o que se desejou investigar em cada um deles e os principais autores que contribuíram para o desenvolvimento das proposições levantadas.

\section{Estratégia organizacional e a visão baseada em recursos}

Para Caldart e Ricart (2004), mesmo após algumas décadas de pesquisas interessadas em desvendar problemáticas relacionadas às estratégias das organizações, percebe-se dentre os estudiosos da área um consenso sobre a ausência de maturidade do tema, pois perguntas-chave ainda permanecem sem respostas, tal como, segundo Markides e Williamson (1994), a que indaga até que ponto diversificações estratégicas contribuem para a conquista de vantagens competitivas para as organizações.

O fato de que cada organização possui uma estratégia macro a ser seguida é reconhecido em termos teóricos e práticos, mas a situação de que cada uma dessas organizações, todas incumbidas de trilhar um caminho estratégico próprio, deveria estudar e implantar estratégias específicas, tanto para as funções básicas da empresa (marketing, recursos humanos, tecnologia da informação, etc.) quanto para uma sustentação que conceda à organização a capacidade de tornar seus objetivos estratégicos tangíveis, ainda não se encontra bem disseminada (ROULAC, 2001).

\begin{tabular}{|c|c|c|}
\hline Temas & O que investigar? & Principais autores \\
\hline Estratégia organizacional & $\begin{array}{l}\text { Abordagens de estudos principais. Fundamentações relacionadas à } \\
\text { visão baseada em recursos. Como se dá a vinculação dos estudos } \\
\text { sobre as estratégias e o desenvolvimento sustentável }\end{array}$ & $\begin{array}{l}\text { Penrose (1959); } \\
\text { Barney (1991); } \\
\text { Merry (1999) }\end{array}$ \\
\hline $\begin{array}{l}\text { Responsabilidade social } \\
\text { empresarial }\end{array}$ & $\begin{array}{l}\text { Contribuições gerais a respeito da responsabilidade social empresarial } \\
\text { e abordagens de estudo sobre o tema que qualificam diferentes pers- } \\
\text { pectivas de pesquisa com as organizações. }\end{array}$ & $\begin{array}{l}\text { Göbbels (2002); } \\
\text { Kaptein, Wempe (2002) }\end{array}$ \\
\hline $\begin{array}{l}\text { Desenvolvimento sustentável } \\
\text { ou sustentabilidade? }\end{array}$ & $\begin{array}{l}\text { O que diferencia essas duas expressões enquanto fenômenos - de } \\
\text { análise e pesquisa - relacionados aos estudos organizacionais. } \\
\text { Compreender qual a especificidade que faz um diferente do outro. }\end{array}$ & $\begin{array}{l}\text { Lélé (1991); } \\
\text { Osorio, Lobato e } \\
\text { Castillo (2005) }\end{array}$ \\
\hline $\begin{array}{l}\text { Vertentes analíticas da } \\
\text { sustentabilidade }\end{array}$ & $\begin{array}{l}\text { As segmentações teóricas da sustentabilidade. As suas divisões his- } \\
\text { tóricas, bem como as características pelas quais cada vertente admite } \\
\text { ser superior que as demais. }\end{array}$ & $\begin{array}{l}\text { Mebratu (1998); } \\
\text { Milne, Kearins, Walton } \\
\text { (2006) }\end{array}$ \\
\hline $\begin{array}{l}\text { Sustentabilidade } \\
\text { organizacional }\end{array}$ & $\begin{array}{l}\text { Quais alicerces devem ser considerados ao definir esse fenômeno } \\
\text { enquanto interessante ao contexto desta pesquisa. }\end{array}$ & $\begin{array}{l}\text { Azapagic (2003); } \\
\text { Jamali (2006) }\end{array}$ \\
\hline
\end{tabular}

Quadro 1 - Estrutura de investigação

Fonte: Dados da pesquisa.

REBRAE. Revista Brasileira de Estratégia, Curitiba, v. 2, n. 2, p. 185-202, maio/ago. 2009 
A estratégia de uma organização engloba, em seus processos analíticos e decisórios, influências críticas advindas de consumidores, fornecedores, governo, stakeholders e assim por diante (BOWMAN; AMBROSINI, 2003). Mediante essa complexa cadeia de relacionamento com a qual as diversas organizações precisam manter contatos contínuos, duas vertentes principais da teoria estratégica, as abordagens inside-out e outside-in, procuram explicar como as empresas traçam seus caminhos estratégicos em diferenciadas redes de relações.

Porter (1991), o principal representante da vertente outside-in, observa a estratégia como um fenômeno oriundo do entendimento de forças competitivas externas à organização e de necessidades que instigam o ato de comprar proferido pelos consumidores. Para o autor é a partir de tal compreensão que a organização alavanca sua vantagem competitiva, uma vez que passa a ocupar uma posição de mercado superior àquelas participadas por seus concorrentes.

Já a abordagem inside-out, também conhecida como a abordagem dos recursos da firma, fundada por Penrose (1959) e consolidada pelos estudos de Barney (1991), com a visão baseada em recursos, adota uma perspectiva na qual a organização constrói sua vantagem competitiva internamente, ao manipular e desenvolver seus recursos, tangíveis e intangíveis, de maneira que sejam mobilizados com $\mathrm{o}$ intuito principal de atender às oportunidades ofertadas pelo mercado.

Apesar da abordagem outside-in ser amplamente debatida, neste artigo opta-se por conceder um destaque às discussões vinculadas à abordagem dos recursos da firma. Tal opção é justificada por Goold, Campbell e Alexander (1998) ao admoestarem que por essa vertente de estudo é possível compreender a relevância das estratégias organizacionais pela influência que elas exercem sobre cada um dos mecanismos de gestão que coordenam o funcionamento das organizações.

A visão baseada em recursos sugere que recursos e capacidades específicos representam os fatores determinantes para que uma firma apresente desempenhos superiores aos de seus concorrentes (RUGMAN; VERBEKE, 1998). De acordo com Wright, Dunford e Snell (2001), as proposições de Wernefelt (1984) podem ser consideradas como as primeiras coerentes, em termos teóricos, sobre os estudos de uma visão organizacional (ou da firma) baseada em recursos.
Os recursos, em síntese, advêm da combinação e do refinamento dos processos da firma, por meio de ações organizacionais específicas identificadas em práticas cada vez mais bem desenvolvidas, pelas quais as organizações adquirem capacidades aprimoradas para se relacionarem com demandas mercadológicas interligadas por consumidores, fornecedores e concorrentes (FREILING; GERSCH; GOEKE, 2008).

Vale ressaltar que antes das contribuições de Wernefelt (1984) existiram os estudos de Penrose (1959), em que é de extrema importância o fato de muitos recursos poderem promover uma variedade de serviços. Conforme afirma a autora é a heterogeneidade, e não a homogeneidade, dos serviços produtivos disponíveis ou potenciais de serem gerados pelos recursos participados pela firma que fazem dela algo único e específico. No entanto, apesar de Penrose (1959) e Wernefelt (1984) serem amplamente citados, a especificação sobre as características necessárias para se constituir uma vantagem competitiva da firma por intermédio da visão baseada em recursos somente esteve presente no trabalho de Barney (1991). Ele admite que os recursos são raros, valorosos, inimitáveis, insubstituíveis e potenciais para conferirem vantagens competitivas sustentáveis para as empresas.

As organizações (ou as firmas), portanto, são reconhecidas como agentes econômicos dotados de fatores escassos e imóveis, bem por isso precisam ser evidenciadas como entidades administrativas que devem ir além de responsabilidades rotineiras, uma vez que compõem diferentes coleções de recursos utilizados em coerência com os processos decisórios ocorrentes em seus respectivos contextos de gestão (HART, 1995).

Por tais considerações é que Bowman e Ambrosini (2003) admoestam que a visão baseada em recursos auxilia a organização a criar não somente uma estratégia organizacional, mas sim uma estratégia organizacional competitiva, pois por ela questões e decisões fundamentais para os caminhos estratégicos a serem percorridos pelas organizações migram de um departamento responsável por decidir o futuro estratégico da empresa e alcançam todo o escopo de gestão controlado pela organização.

Em suma, a estratégia organizacional regida por princípios veiculados pela visão baseada em recursos é aquela decidida, no ambiente interno da organização, pela indicação das principais vantagens e desvantagens de cada ação a ser tomada e pelo 
conhecimento das forças e fraquezas participadas pela empresa naquele momento de decisão. Logo, a estratégia corporativa da empresa é composta por decisões tomadas em espaços ocupacionais estratégicos da organização que objetivam conduzir e estimular, de maneira eficiente, processos que desemboquem em uma evolução global da empresa (CALDAR'T; RICART, 2004).

Essa evolução se dá em um ambiente mercadológico dinâmico e mutante, o qual exige que as organizações tomem determinadas atitudes que venham a garantir sua permanência como agente competitivo em um cenário econômico continuamente conturbado (RUGMAN; VERBEKE, 1998). Tais ações não estão fechadas em um ciclo de dependência plenamente controlado pelas organizações, pois, ainda que de maneira inconsciente, cada uma das opções estratégicas selecionadas pelas organizações apresenta consequências para uma ampla gama de atores sociais (CALDART; RICART, 2004). Essa interdependência entre organização, mercado e sociedade não é estanque, uma vez que exigências legais, de consumidores e de fornecedores mudam continuamente (ROULAC, 2001). O cenário apresentado atesta a volatilidade das estratégias organizacionais, pois, em face de inúmeras transformações, os efeitos positivos de uma ação estratégica eficaz sobre os diversos atores sociais com os quais as organizações se relacionam passam a ser usufruídos por espaços de tempo cada vez menores.

Cientes de que o período de usufruto de cada uma de suas respectivas ações estratégicas é gradativamente menor, as organizações procuram validar seus intentos por caminhos estratégicos que indiquem, para os seus contextos de gestão e para todas as cadeias de atores sociais com as quais se relacionam, a realização de ações fundamentadas em conquistar interesses de longo prazo, tal como o desenvolvimento sustentável. A interação entre procedimentos organizacionais estratégicos e causas sustentáveis concede às organizações uma capacidade acentuada de se adaptarem continuamente a condições ambientais continuamente mutáveis.

Como admoesta Merry (1999), a abordagem da sustentabilidade em ações organizacionais que conciliam interesses estratégicos e preocupações com o desenvolvimento sustentável expressa um cenário caracterizado pela possibilidade das organizações constituírem incontáveis ciclos de vida ao longo de sua trajetória, simplesmente por considerarem em suas rotinas de gestão os seguintes fatos: as condições ambientais podem mudar, as atividades organizacionais contemporâneas podem afetar a sobrevivência de gerações futuras e a existência de uma interação coevolucionária e circular entre essas atividades organizacionais e aquelas condições ambientais.

Essa preocupação organizacional de responder ao desafio de contribuir para o alcance de um desenvolvimento sustentável tem permitido a emergência de inúmeros caminhos estratégicos interessados em respaldar esse interesse, os quais assumem diferentes denominações, tais como responsabilidade social empresarial e sustentabilidade organizacional. As seções que seguem procuram aprofundar as discussões relacionadas a cada um desses caminhos estratégicos mencionados, em prol de que ao final deste artigo possa-se indicar uma hierarquização desses caminhos em relação à representatividade estratégica que possuem para o alcance do desenvolvimento sustentável.

\section{Responsabilidade social empresarial}

Com o advento do paradigma do desenvolvimento sustentável no início dos anos 1980, as organizações começaram a aprimorar suas visões puramente econômicas por meio de ajustes estratégicos que se relacionariam com as pressões ambientais e as transformações sociais cada vez mais constantes (ROBINSON, 2000). Os anos 1990 testemunharam uma nova modificação paradigmática inspirada pela apreciação social sobre o fato das empresas optarem por, em vez de realizarem uma simples gestão ambiental técnica, assumirem a responsabilidade de desenvolverem métodos de gestão comprovadamente sustentáveis (JAMALI, 2006).

As organizações, até então, apresentavam-se mais inclinadas a possuírem práticas de avaliação que privilegiavam planos financeiros de curto prazo e preteriam aquelas que contemplassem métodos avaliativos que agrupassem os impactos sociais, ambientais e econômicos gerados em decorrência das atividades operacionais das organizações (HARDJONO; van MARREWIJK, 2001).

De acordo com Jamali (2006) a concepção da responsabilidade das organizações em relação ao meio ambiente e a sociedade tem evoluído gradativamente em termos teóricos e termos práticos, uma vez que as empresas passam a compor suas análises 
pela consideração da função tradicional econômica que possuem (produção, empregos, crescimento), mas com a prerrogativa de observar e garantir a conservação ambiental e a consideração dos impactos sociais e do bem-estar dos seres humanos.

Göbbels (2002), no entanto, considera a responsabilidade social como um termo "brilhante", ao admitir que tais palavras têm algum significado, o qual não participa de um consenso junto aos ambientes organizacionais. Frequentemente, a responsabilidade social de uma empresa é estabelecida por meio de contribuições extraídas de uma panaceia conceitual, dentro da qual se impera o intuito não muito comprovado de resolver a pobreza mundial, a exclusão social e a degradação do meio ambiente (van MARREWIJK, 2003).

Associações de empregadores fazem questão de enfatizar o caráter voluntário das ações vinculadas à responsabilidade social empresarial. Órgãos governamentais e organizações não governamentais acreditam que uma parceria entre instâncias públicas e privadas pode promover o rejuvenescimento de comunidades desgastadas monetariamente e socialmente. Algumas disciplinas de gestão têm reconhecido que a responsabilidade social empresarial cumpre propósitos semelhantes aos movimentos regidos por interesses de alcançar melhores índices de qualidade de vida, programas de marketing menos ofensivos, práticas de comunicações mais transparentes, retornos financeiros coerentes com o desenvolvimento organizacional e preservação social e ambiental e melhores práticas de gestão de recursos humanos (van MARREIWIJK, 2003).

Cada uma dessas preocupações possui um alicerce localizado nos preceitos de uma responsabilidade social e empresarial, os quais precisam estar alinhados aos contextos e aos desafios enfrentados pelas organizações. Os conceitos atuais, no entanto, estão vinculados a grandes jogos de interesses. Para Henderson (2001) a responsabilidade social empresarial é muito ampla em seu escopo para que seja algo efetivamente relevante para as organizações. Ele ainda declara que não há solidez e consenso, relacionados à responsabilidade social empresarial, que concedam uma base coerente para efetivas ações organizacionais. A lacuna de uma definição mal proferida sobre a responsabilidade social empresarial e a consequente diversidade de terminologias, definições e modelos conceituais dificultam o debate acadêmico e a realização de pesquisas com apurado valor científico (GÖBBELS, 2002).
Alguns autores, de acordo com van Marrewijk (2003), ainda asseveram que persiste a necessidade de se ampliar o conceito de responsabilidade social empresarial, mesmo que tal amplitude cause certo desconforto para reais implementações corporativas ou respaldadas discussões científicas. A exemplificação dessa miscelânea de contribuições em relação à responsabilidade social empresarial está em sua evolução histórica, dividida principalmente por quatro abordagens mais relevantes: a abordagem do acionista, a abordagem do stakeholder, a abordagem social e a abordagem filantrópica. A fim de que o leitor possa melhor compreender tais vertentes analíticas sobre a responsabilidade social empresarial expõe-se o Quadro 2.

De todas as abordagens, a social parece mais coerente como resposta estratégica para as transformações contemporâneas e para os novos desafios enfrentados pelas organizações. A compreensão dessa realidade requer, por parte das organizações atuais, um ato de repensar suas representatividades mediante a sociedade e as consequências de suas atividades em termos de melhor se comunicar com os diversos arranjos sociais direta e indiretamente relacionados com o operar das empresas.

Apesar de todo esse alicerce contributivo, a responsabilidade social empresarial, quando considerada como um fenômeno de pesquisa, é admitida como uma parcela muito menor do todo que contribui para o alcance de um desenvolvimento sustentável. Tal afirmativa é considerada como verdadeira para muitos autores - dentre eles Kaptein e Wempe (2002) -, os quais por meio da teoria da integridade corporativa consideram que os estudos sobre responsabilidade social empresarial e sustentabilidade organizacional, ao longo de suas trajetórias acadêmicas, mostraram diferentes caminhos que apenas recentemente começaram convergir.

No passado a sustentabilidade era debatida somente por preceitos ambientais enquanto a responsabilidade social empresarial caracterizava-se por aspectos puramente sociais, tais como os direitos humanos. Mais recentemente, alguns autores, como van Marrewijk e Werre (2003), consideram, equivocadamente, a responsabilidade social empresarial e a sustentabilidade organizacional como sinônimos. Kaptein e Wempe (2002) recomendam uma distinção tênue entre ambas: associar responsabilidade social empresarial a aspectos que unem os interesses de pessoas e organizações e sustentabilidade organizacional 
a discussões que tratem dos princípios organizacionais. Assim, a responsabilidade social empresarial trata de questões como transparência, diálogo com os stakeholders e atos de reportar ações sustentáveis, enquanto a sustentabilidade organizacional prioriza a criação de valor, a gestão ambiental, sistemas de produção ambientalmente amigáveis, gestão do capital humano e assim por diante. Kaptein e Wempe (2002) estabelecem, por suas contribuições, que a sustentabilidade organizacional é uma meta maior, dentro da qual a responsabilidade social empresarial é compreendida como um estágio intermediário, no qual as empresas procuram meios que viabilizem práticas de gestão que integrem as dimensões da sustentabilidade.

Mediante tais considerações os mesmos autores concordam sobre a necessidade de se providenciar pesquisas que mantenham essa distinção conceitual. Para eles os três aspectos mais relevantes da sustentabilidade (econômico, social e ambiental) precisam ser inseridos em discussões referentes às responsabilidades pelas quais as organizações precisam estar comprometidas em solucionar e responder (KAPTEIN; WEMPE, 2002).

Esses autores se alinham às proposições de Savitz e Weber (2006) ao afirmarem que a responsabilidade social empresarial, em seus escopos econômicos, sociais e ambientais, dependem de três personagens fundamentais: das pessoas, do Planeta e do lucro. Essa abordagem explicativa é reconhecida internacionalmente como os 3Ps (people, planet and profit). O pilar people refere-se ao tratamento do capital humano de uma empresa ou sociedade por meio de salários justos, adequação à legislação trabalhista e ambiente de trabalho agradável. O pilar planet compõe o capital natural de uma empresa ou sociedade, é o sustentáculo ambiental do tripé. E profit, compreende o resultado econômico positivo de uma empresa, alinhado aos preceitos dos outros dois pilares (SAVITZ; WEBER, 2006).

\begin{tabular}{|c|c|c|}
\hline Abordagem & Contextualização & Autores \\
\hline Acionista & $\begin{array}{l}\text { A responsabilidade social de uma organização é diretamente proporcional aos } \\
\text { lucros gerados pelo desempenho de suas atividades. O acionista, ator que busca } \\
\text { a maximização dos retornos sobre seus investimentos, é a prioridade da empresa. } \\
\text { As atividades de responsabilidade social não constam em seus deveres, mas sim } \\
\text { representam ações a serem desenvolvidas pelos representantes governamentais. } \\
\text { Essa abordagem pode ser interpretada como aquela em que a empresa pratica a } \\
\text { responsabilidade social somente em atos que contribuam para o alcance de suas } \\
\text { metas de negócios, dentre elas a criação de uma cadeia de valor sustentável (em } \\
\text { termos financeiros) e duradoura para os proprietários do empreendimento. }\end{array}$ & $\begin{array}{l}\text { Friedman (1962), } \\
\text { Quazi e O'Brien (2000) }\end{array}$ \\
\hline Stakeholder & $\begin{array}{l}\text { Essa abordagem indica que as organizações não importam apenas em termos con- } \\
\text { tábeis para seus acionistas, mas também por uma série de interesses que deveriam } \\
\text { ser analisados, balanceados e atendidos mediante as expectativas dos diversos } \\
\text { stakeholders que se relacionam com a empresa, os quais podem afetar ou serem } \\
\text { afetados pelas atividades operacionais e pelos objetivos que compõem as rotinas } \\
\text { estratégicas das organizações. }\end{array}$ & Freeman (1984) \\
\hline Social & $\begin{array}{l}\text { Essa abordagem possui seus princípios mais alinhados aos propósitos de uma ver- } \\
\text { dadeira responsabilidade social empresarial, uma vez que admite que as empresas } \\
\text { possuem uma responsabilidade sobre a sociedade como um todo, por serem parte } \\
\text { integrante de toda a estrutura que rege esta sociedade. As empresas, por consequência } \\
\text { dessa responsabilidade, operam por meio de um consentimento público no intuito } \\
\text { de suprirem os anseios e necessidades da sociedade. }\end{array}$ & Göbbels (2002) \\
\hline
\end{tabular}

Quadro 2 - A evolução histórica das abordagens da responsabilidade social empresarial Fonte: Adaptado de FREEMAN, 1984; FRIEDMAN, 1962; QUAZI; O’BRIEN, 2000; van MARREWIJK, 2003. 
Kaptein e Wempe (2002) e Savitz e Weber (2006) asseveram, portanto, que a boa gestão desses 3Ps conflui em práticas coerentes e efetivas de responsabilidade social empresarial, as quais, se somadas, proporcionam parte considerável dos aspectos necessários para se alcançar a sustentabilidade organizacional. A Figura 1 ilustra essa articulação e relacionamento.

Compreendida a responsabilidade social empresarial como fenômeno integrante de uma meta maior, a sustentabilidade organizacional, desse momento em diante opta-se por padronizar o discurso deste artigo ao privilegiar a utilização da expressão "sustentabilidade organizacional". Como foi defendido que a sustentabilidade organizacional e a responsabilidade social empresarial não são sinônimas, logo, é imprescindível uma exploração conceitual do que vem a ser a sustentabilidade organizacional. Discussões que deem conta de proferir essa qualificação definitiva são exploradas nas seções a seguir.

\section{Desenvolvimento sustentável ou sustentabilidade?}

Após a inserção do termo "desenvolvimento sustentável" no cenário internacional, observou-se uma falta de consenso sobre o que realmente tal expressão poderia significar e também sobre o que diferencia o desenvolvimento sustentável da sustentabilidade. Essas são as principais indagações a serem respondidas por meio da presente seção. Justifica-se essa preocupação pelo fato de que, se não for mantida uma coerência discursiva, corre-se o risco de se ceder à generalidade e à a mbiguidade observada no relacionamento das palavras "desenvolvimento" e "sustentabilidade" (LÉLÉ, 1991).

A partir do lançamento do World Conservation Strategy, em 1980, muitos começaram a tentar definir o desenvolvimento sustentável como um fenômeno necessário de ser expresso em outras palavras. Dentre as incontáveis nomenclaturas concedidas, destacam-se: um valor de transformação (CLARK, 1989), reorganização social (GORE, 1992), uma expressão visionária (LEE, 1993), desenvolvimento moral (ROLSTON, 1994) e processo ininterrupto de transformações (VIEDERMAN, 1994).

Todas essas terminologias ramificaram-se, principalmente, do conceito de desenvolvimento sustentável apresentado pela Comissão de Brundtland em um relatório apresentado na World Comission on Environment and Development (WCED) em 1987. Tal conceito, de acordo com Gladwin, Kennelly e Krause (1995), foi amplamente aceito por milhares de organizações governamentais, empresas e instituições internacionais, por uma assimilação normativa e abstrata desprovida de qualquer interesse de investigar a essência do conceito em perspectiva.

Osorio, Lobato e Castillo (2005) também combatem essa generalização ao afirmar que as discussões em torno de um debate conceitual não podem ser aceitas como algo óbvio e proveniente de propostas simplistas compostas por definições não muito detalhadas e deficientes de complexidade. De acordo com os autores, assim acontece com o desenvolvimento sustentável e com a sustentabilidade, que se tornaram meras expressões inseridas em um processo inconsciente de homogeneização global.

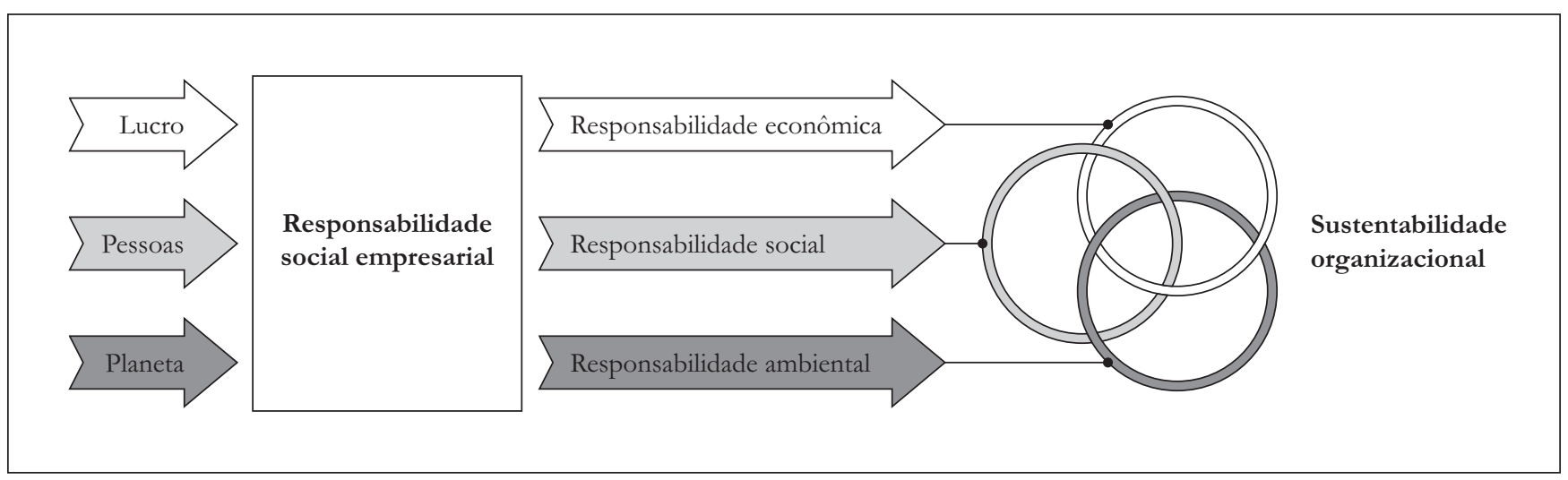

Figura 1 - Sustentabilidade organizacional e responsabilidade social empresarial - suas relações Fonte: Adaptado de KAPTEIN; WEMPE, 2002; SAVITZ; WEBER, 2006. 
Ao investigar mais profundamente o conceito de "sustentabilidade", os autores consideram que este é dividido em duas vertentes principais: normativa e positiva. A primeira refere-se ao que deveria ser feito e a segunda demonstra a realidade. Em outras palavras, a sustentabilidade positiva trabalha com análises científicas a respeito do desenvolvimento sustentável e da sustentabilidade, todas elas baseadas nos choques entre a economia e a ecologia.

Embora sejam ricas, tais análises ainda não chegaram a um acordo sobre o que deve ser feito e o que precisa ser alcançado para um desenvolvimento sustentável. A sustentabilidade normativa, por sua vez, está intensamente vinculada a uma postura conceitual institucional (MEBRATU, 1998), por se preocupar com os acordos e as propostas institucionais que envolvem a expressão desenvolvimento sustentável (OSORIO; LOBATO; CASTILLO, 2005).

Independente de a abordagem ser positiva ou normativa é válido esclarecer que o conceito de sustentabilidade é uma adaptação de uma noção utilizada no domínio agrobiológico. Nessa área o termo é definido como a capacidade de um sistema manter sua produtividade mesmo em situações de adversidade (JIMÉNEZ HERRERO, 2000). Com o desenvolver da história o conceito foi sendo aplicado em diversas áreas do conhecimento, o que permitiu a inclusão de aspectos referentes aos sistemas naturais por uma via ecológica e preservacionista.

No estágio final de construção do conceito de sustentabilidade, o termo acabou assumindo uma perspectiva de relevância ambiental, na qual os critérios econômicos, sociais e culturais começaram a ser considerados gradativamente (JIMÉNEZ HERRERO, 2000; OSORIO; LOBATO; CASTILLO, 2005).

Percebe-se que a disseminada similaridade entre sustentabilidade e desenvolvimento sustentável não se confirma pela disparidade de suas fundamentações conceituais. Mediante esse reconhecimento, os conceitos diferem. Enquanto a sustentabilidade refere-se à capacidade de manter algo em um estado contínuo, o desenvolvimento sustentável envolve processos integrativos que buscam manter o balanço dinâmico de um sistema complexo a longo prazo.

A sustentabilidade, então, pode ser considerada a ideia central do desenvolvimento sustentável, uma vez que a origem, os espaços, os períodos e os contextos de um determinado sistema se integram para um processo contínuo de desenvolvimento (JIMÉNEZ HERRERO, 2000).
Para Lélé (1991), a sustentabilidade possui um significado constituído por três pilares principais: literal, ecológico e social. O significado literal referese à continuação do nada; o significado ecológico refere-se à manutenção de uma base ecológica para a vida humana, dentro de um determinado período de tempo, o que indica uma preocupação com as gerações contemporâneas e futuras; já o significado social prioriza a manutenção dos valores sociais, das instituições, das culturas e das demais características sociais (LÉLÉ, 1991).

Em relação ao desenvolvimento sustentável, Lélé (1991) argumenta que duas são as possíveis interpretações: (1) crescimento sustentável (o que para ele é contraditório e trivial); e (2) realização de objetivos tradicionais, descritos como políticos e significativos. Fergus e Rowney (2005) consideram que essas interpretações concedidas por Lélé (1991) indicam que o desenvolvimento sustentável é um fenômeno consequente da estabilidade de uma série de outros fenômenos menores e interligados. Essa afirmação se justifica, pois o próprio Lélé (1991) assevera que as duas interpretações concedidas podem ser traduzidas, cada uma, em uma simples palavra: a primeira pode denunciar o desenvolvimento sustentável como um processo, uma vez que busca o crescimento; a segunda identifica o termo como um objetivo, visto que seu intuito principal está em satisfazer necessidades básicas.

Osorio, Lobato e Castillo (2005) complementam o discurso de Lélé (1991) ao considerarem que sustentabilidade e desenvolvimento sustentável se diferem quanto à busca de seus objetivos finais. A sustentabilidade representa um argumento inquestionável, pois, independente de seu objetivo final, este deve ser alcançado por um equilíbrio de utilização e consumo de recursos naturais. A busca de uma sustentabilidade ambiental, por exemplo, é parte integrante de uma meta maior.

O desenvolvimento sustentável se baseia na preservação dos recursos naturais, ou seja, busca os mesmos objetivos da sustentabilidade e é complementado pela busca de um equilíbrio social, cultural e econômico (OSORIO;LOBATO; CASTILLO, 2005).

Em síntese, os autores Lélé (1991), Jiménez Herrero (2000) e Osorio, Lobato e Castillo (2005) concordam que o desenvolvimento sustentável constitui a direção futura do progresso humano, por meio de processos ocorrentes em três dimensões principais: econômica, ecológica e social. 
Quando a economia se alia à ecologia, o desenvolvimento sustentável é aceito como um objetivo e definido como um meio para o progresso humano por uma abordagem integrativa e inclusiva para as gerações contemporâneas e futuras. Quando as perspectivas ecológicas se somam às sociais, o desenvolvimento sustentável passa a ser assumido como um fenômeno processual e entendido como um discurso que integra conhecimentos, filosofias e ferramentas de mensuração altamente eficazes.

Em relação a uma organização, portanto, o desenvolvimento sustentável é tanto um objetivo quanto um processo, ou seja, representa uma meta maior constituída de metas menores a serem alcançadas em prazos específicos. Se o desenvolvimento sustentável, enquanto objetivo, relaciona economia e ecologia e, enquanto processo, interliga ecologia e sociedade, enquanto ação organizacional exige a vinculação entre economia, ecologia e sociedade.

A sustentabilidade compõe, assim, ações mais objetivas que propiciam o alcance de um desenvolvimento sustentável. Se considerada cada meta organizacional como um objetivo final em busca de um equilíbrio sistêmico, considera-se cada uma delas relacionada à sustentabilidade.

A soma de tais metas, ou seja, a adição de sucesso desses objetivos sustentáveis é o que permite a realização de um desenvolvimento sustentável, uma vez que a sustentabilidade busca o equilíbrio de qualquer sistema e o desenvolvimento sustentável busca a soma desses equilíbrios e mais um equilíbrio maior composto por todas as interações entre esses sistemas.

Compreendida essa dimensão de relacionamento entre desenvolvimento sustentável e sustentabilidade, admite-se que o desenvolvimento sustentável é composto por inúmeras sustentabilidades, dentre elas a sustentabilidade das organizações, ou sustentabilidade organizacional, termo esse que será melhor explorado, porém, antes de se alcançar essa seção temática, é necessária a apresentação de algumas vertentes analíticas dos estudos sobre sustentabilidade, a fim de que o estudo em desenvolvimento conquiste maiores fundamentações científicas. Essas vertentes são introduzidas na seção sequente.

\section{As vertentes analíticas da sustentabilidade}

Grande parte da literatura a respeito da sustentabilidade e do próprio desenvolvimento susten- tável está fundamentada em simultâneas limitações e reduções. Como uma alternativa a essa deficiência, um número considerável de autores tem procurado adquirir uma argumentação mais vinculada a certos padrões éticos para que, assim, suas contribuições possam apresentar maior relevância científica (MEBRATU, 1998).

Alguns admitem que as ciências, por suas diversas contribuições, são as grandes responsáveis pela crise ambiental. Todas essas tendências literárias levaram a uma polaridade duvidosa entre duas correntes de pensamento principais: a holística e a reducionista (MEBRATU, 1996).

Mais recentemente, grupos de pesquisa alheios a essa inflexibilidade começaram a ter maior representatividade ao reconhecerem uma complementaridade entre as contribuições reducionistas e holísticas. Alguns observam duas abordagens distintas dentro desse grupo que podem ser denominadas pelo próprio domínio conceitual que as originou. A primeira advém daqueles que possuem um grande apelo holístico, logo, assumem o todo como referência principal para suas concepções e coletam a contribuição das partes que compõem esse todo apenas quando necessário. A segunda é composta por pesquisadores rigidamente reducionistas, ou seja, aqueles que têm as partes que formam o todo como ponto de partida para suas análises, para, posteriormente, considerar esse todo como uma extensão linear resultante de uma soma não complexa das partes (MEBRATU, 1998).

Nas duas abordagens, os pesquisadores que as representam afirmam com veemência estarem vinculados à escola holística. No entanto, de acordo com Mebratu (1998), em ambos os casos eles falham no que mais importa: na interação entre as partes e o todo, e o todo e o ambiente.

Essas abordagens levam a uma estrutura conceitual, provida de soluções complexas praticamente impossíveis de serem implementadas. A falha epistemológica presente nessas vertentes holísticas e reducionistas pode ser superada pelo simples reconhecimento de que o pensamento holístico está baseado nas partes, no todo e, mais importante, na interação entre essas partes, o todo e o ambiente.

Anterior a essa segmentação entre holismo e reducionismo, e em verdade muito mais citada, está a segmentação dos conceitos relacionados à sustentabilidade articulada por uma estrutura conceitual ecológica, repartida em ecologia fraca e ecologia 
profunda. De acordo com Clarke (1993), a ecologia fraca compreende o tratamento dos problemas ambientais sem a análise de suas principais causas e sem confrontarem-se os choques filosóficos, políticos e econômicos que circundam as tomadas de decisões em relação às fatalidades naturais.

O mesmo autor relata que a ecologia profunda observa a riqueza e a diversidade da vida como valores donos de si mesmos e assume que os seres humanos não possuem o direito de reduzi-los, exceto em taxas de consumo necessárias para satisfazer suas necessidades básicas. Os defensores da ecologia profunda, segundo Mebratu (1998), enfatizam a necessidade de se manter a diversidade cultural e a diversidade nos arranjos sociais para que o Planeta continue a existir.

Essas vertentes, forte e fraca, estão bem vinculadas às proposições da sociologia ambiental. No entanto, dentro das pesquisas organizacionais também se nota a tendência de se segmentar os estudos da sustentabilidade. Milne, Kearins e Walton (2006) afirmam ser possível discernir dois padrões principais de pensamentos que conectam a amplitude dos discursos sociais e ambientais à sustentabilidade organizacional.

A mais dominante dessas perspectivas assume uma linha funcionalista, ao privilegiar uma visão gerencial do conceito de sustentabilidade, o que é justificado pela concepção de que por melhorias incrementais é possível efetivar e avançar na denominada preocupação organizacional em relação à sustentabilidade.

O segundo padrão de pensamento, totalmente oposto ao primeiro, é mais radical e crítico, por sugerir que mudanças fundamentais sobre os métodos de gestão contemporâneos são imprescindíveis para se alcançar uma sustentabilidade organizacional. Essa abordagem admite que já existem crises, e outras iminentes que começam a se mostrar, causadas pela superexploração de recursos naturais, bem como pela distribuição injusta desses recursos.

Tais circunstâncias promovem o caráter extrapolado de crescimento e consumo de algumas regiões do Planeta impregnadas por superpopulações. Em essência, essa segunda vertente fundamentase na necessidade de se viver dentro dos limites da natureza, uma vez que existem limites para o crescimento (MILNE; KEARINS; WALTON, 2006).

A perspectiva incremental (ou funcionalista), rotulada por Egri e Pinfield (2007) como reforma ambientalista, está impregnada por um tecno-otimismo. A tecnologia, segundo os autores, é vista simultaneamente como necessária para o desenvolvimento científico e econômico e como a solução para o gerenciamento dos riscos ambientais. Os autores dessa linha de pensamento tendem a priorizar cada vez menos a frouxidão do conceito de sustentabilidade, por preferirem investigar como tais termos podem ser operacionalizados em diversas áreas de negócios, designando as organizações como os principais agentes para promover a sustentabilidade (EGRI; PINFIELD, 2007).

Alguns autores, como Hart (1995) e Porter e Van der Linde (1995), já afirmavam que a ação das empresas em prol da sustentabilidade e do meio ambiente somente aconteceria por situações que se caracterizassem por um ganho mútuo, ou seja, ser boa para as organizações e boa para o meio ambiente. Teóricos mais críticos e radicais em estudos organizacionais representam um grupo menor nessas discussões, mas geralmente estão unidos por seus preceitos sobre o que vem a ser uma sustentabilidade forte e mais ecocêntrica, totalmente oposta à abordagem tecnocêntrica apregoada pela escola anterior (MILNE; KEARINS; WALTON, 2006).

Definições sobre sustentabilidade forte enfatizam não somente uma alocação de recursos eficiente ao longo do tempo, mas também uma distribuição justa de recursos e oportunidades entre as gerações contemporâneas e futuras, além de uma escala de atividade econômica coerente com a capacidade de suporte dos ecossistemas (DALY, 1992).

Wackernagel e Rees (1996) argumentam que a sustentabilidade não passa de um conceito que, em simples palavras, traduz o modo de viver confortável e pacífico dentro de níveis suportados pela natureza. Gladwin, Kennelly e Krause (1995) apresentam suas dúvidas em relação a abordagens que tratem da sustentabilidade como um fenômeno consequente da ação organizacional, e são extremamente críticos quanto à prática constante de se basear os modelos de gestão em premissas da ecoeficiência.

Dentro desse contexto, os adeptos da ecologia profunda, no que tange às pesquisas relacionadas às ciências organizacionais, tomam como uma de suas bases alguns alicerces do movimento da justiça ambiental e das teorias políticas (TAYLOR, 2000). Por tais contribuições, seus pesquisadores alegam que existe muito mais a ser explorado pelas organizações do que simples práticas ecoeficientes, ou seja, 
as empresas podem fazer muito mais no intuito de avançarem efetivamente em causas ambientais e sustentáveis (MILNE; KEARINS; WALTON, 2006).

Exposta às vertentes que analisam a sustentabilidade, acredita-se, segundo Kaptein e Wempe (2002), que a sustentabilidade organizacional requer um diálogo entre essas vertentes tão enraizadas em seus propósitos. Os autores argumentam que a sustentabilidade de uma organização, diferentemente de sua responsabilidade social, vai além de questões que envolvam transparência, diálogo com stakeholders e atos de reportar ações sustentáveis, ao priorizar a criação de valor para a empresa e para as diversas comunidades com as quais se relaciona, a constituição de práticas efetivas de gestão ambiental, a elaboração de sistemas de produção benéficos à natureza e a disseminação de uma eficiente gestão do capital humano (KAPTEIN; WEMPE, 2002).

Compreendida a sustentabilidade organizacional como uma das manifestações que dialoga com todas as vertentes analíticas apresentadas da sustentabilidade, apresenta-se a próxima seção com o interesse de defini-la.

\section{Definindo a sustentabilidade organizacional}

A sustentabilidade, de acordo com Dyllick e Hockerts (2002), tornou-se o mantra do século XXI, por agregar promessas de evolução social em um mundo mais justo e mais rico, dentro do qual o meio ambiente e as conquistas culturais deveriam ser preservadas para as gerações futuras. Tais promessas, no entanto, esbarram em algumas esperanças e medos, ambos motivos de orientações e desafios para muitos pesquisadores. A busca por um crescimento econômico e uma equidade social tem percorrido um vasto caminho, impregnado por possíveis soluções, nos últimos 150 anos. Ao agrupar a preocupação de preservar os sistemas naturais, a sustentabilidade agrupa os principais desafios da humanidade. Um resultado considerável de toda esta discussão está na adoção do termo "desenvolvimento sustentável" nos discursos organizacionais (DYLLICK; HOCKERTS, 2002).

A relevância dessa consideração iniciada pelas empresas está no fato dos sistemas industriais e de prestação de serviços causarem e determinarem o comportamento dos fluxos de materiais e energia na sociedade. Embora as indústrias sejam vistas, também, como fonte de degradações ambientais e prejuízos sociais, elas representam parte essencial dos processos de desenvolvimento e geração de riquezas. São, portanto, importantes atores sociais, e bem por isso devem assumir lideranças em ações que se preocupem em garantir um futuro sustentável (AZAPAGIC; PERDAN, 2000).

As organizações envolvidas ativamente no debate sobre sustentabilidade tentam identificar maneiras pelas quais elas podem desenvolver novas metodologias de gestão que permitam aprimorar as práticas relacionadas aos pilares da sustentabilidade e, consequentemente, contribuir de maneira mais coerente com o desenvolvimento sustentável. Uma das maiores forças representativas quanto ao interesse de uma sustentabilidade organizacional são as legislações, as quais começam a ser reajustadas com o intuito de melhor promover o desenvolvimento sustentável (AZAPAGIC, 2003).

O elevado interesse pela sustentabilidade organizacional é resultado da globalização, pela qual a complexidade do mundo dos negócios foi elevada. Por ela novas demandas começaram a surgir e as empresas passaram a ter que desenvolver mecanismos que comprovassem o elevado grau de transparência inserido em seus processos de negociação, além de práticas que as validassem como empresas praticantes de uma cidadania corporativa. Além do mais, enquanto os governos tradicionalmente haviam assumido a responsabilidade de incrementarem as condições de vida das populações ao redor do mundo, as necessidades sociais têm excedido a capacidade dos órgãos e representantes políticos de supri-las. Nesse contexto, o ponto principal de toda essa discussão está em verificar a representatividade das organizações quanto aos seus processos de gestão junto à sociedade (JAMALI, 2006).

Cada organização, de acordo com van Marrewijk e Werre (2003), deveria escolher sua específica ambição e abordagem com respeito à sua sustentabilidade, de maneira que os objetivos e os intentos organizacionais sejam unidos aos processos de planejamento estratégico, por meio de decisões que apresentem respostas apropriadas para as circunstâncias que circundam o contexto sobre o qual a gestão organizacional acontece. Um padrão diferenciado de definições e abordagens da sustentabilidade organizacional pode auxiliar a organização a encontrar uma trilha adequada, ou seja, relacionada 
ao cenário em que opera e aos valores que regem os seus propósitos. Van Marrewijk (2003) elaborou um modelo de hierarquização que qualifica as empresas em seis diferentes padrões de alcance e desenvolvimento da sustentabilidade organizacional, os quais são explicados no Quadro 3.

Uma vez que enfrentam circunstâncias diferenciadas e operam por diversos sistemas de valores, as organizações desenvolvem diferentes manifestações de uma sustentabilidade organizacional. Essas divergências podem ser compreendidas como fenômenos intrínsecos a diferentes níveis da sustentabilidade de determinada organização. Esses níveis refletem as motivações para se incorporar a sustentabilidade organizacional nas práticas do negócio, ou seja, podem categorizar a organização quanto ao tipo de sustentabilidade organizacional que busca (van MARREWIJK, 2003).

\section{Pré-sustentabilidade organizacional}

Neste padrão não se observa qualquer ambição para se alcançar a sustentabilidade organizacional. No entanto algumas ações rotuladas como sustentáveis podem ser iniciadas quando exigidas por pressões externas (legislações e exigência dos consumidores). Um monitoramento rígido e constantes aprimoramentos são necessários a fim de que a empresa possa desenvolver o que entende sobre sustentabilidade organizacional.

2 A sustentabilidade organizacional em conformidade com a legislação

Neste padrão de qualificação a sustentabilidade organizacional consiste na provisão de bem-estar para a sociedade dentro dos limites previstos por normatizações legais. Além disso, as organizações precisam responder a algumas demandas de caridade e reivindicações oriundas de atores sociais diversos. A motivação para a sustentabilidade está em percebê-la como algo imposto, uma obrigação ou um comportamento correto.

3 A sustentabilidade organizacional orientada pelo lucro

Este padrão de sustentabilidade organizacional é caracterizado por uma integração dos aspectos sociais, éticos e ecológicos junto às operações realizadas pelas empresas, ou seja, junto aos seus processos de tomada de decisões, desde que tal opção contribua com algum retorno financeiro para a organização. A motivação para a sustentabilidade organizacional está relacionada ao desenvolvimento financeiro do negócio. A sustentabilidade organizacional, portanto, apenas será promovida se for rentável.

4 A sustentabilidade organizacional consciente (focada na conservação)

Neste padrão existe um interesse por equilibrar questões econômicas, sociais e ecológicas, todas colocadas em um mesmo patamar de importância. As iniciativas relacionadas a essa sustentabilidade organizacional vão além das conformidades legais e não se limitam às preocupações sobre os lucros. A motivação para a sustentabilidade organizacional está no potencial humano, na responsabilidade social das empresas e no cuidado com o Planeta.

5 Sustentabilidade organizacional sinérgica

Este padrão de sustentabilidade organizacional busca por soluções funcionais e bem elaboradas que criem valor nos escopos econômicos, sociais e ecológicos. Esta performance é evidenciada por diferentes índices de desempenhos organizacionais, os quais são conquistados por uma abordagem de ganho mútuo participada por todos os stakeholders mais relevantes da cadeia de relacionamento da organização. A motivação para a sustentabilidade organizacional está em reconhecer a sustentabilidade como um fenômeno importante por si só, especialmente por ser compreendida como uma ação inevitável para o progresso da empresa.

6 Sustentabilidade organizacional holística

Este padrão identifica que a sustentabilidade organizacional está extremamente integrada e embutida em cada um dos aspectos envolvidos aos processos de gestão e, bem por isso, objetiva contribuir para a qualidade, manutenção e continuação da vida de todos os seres e instituições, tanto no presente quanto no futuro. A motivação para a sustentabilidade organizacional está em observar a sustentabilidade como a única alternativa de resposta à crise do meio ambiente. Assim, cada pessoa e organização possuem uma responsabilidade universal para com todos os outros seres vivos do Planeta.

Quadro 3 - Os padrões de sustentabilidade organizacional Fonte: van MARREWIJK, 2003. 
Van Marrewijk e Werre (2003) ressaltam que a sustentabilidade organizacional é propícia a cada realidade empresarial. Para eles, cada organização possui a sua definição do que vem a ser uma sustentabilidade organizacional, tanto que esse conjunto diferenciado de definições implica que não existe algo tangível que possa manifestar a existência dessa sustentabilidade organizacional. Os autores consideram que as características de um nível específico de sustentabilidade organizacional estão embutidas nos respectivos arranjos institucionais: quanto mais ambiciosa a sustentabilidade da organização, mais complexa sua estrutura organizacional.

Dyllick e Hockerts (2002) asseveram que, mesmo sendo a sustentabilidade organizacional específica a cada organização que a busca, existe um consenso de que tal tipo de sustentabilidade já está situada em debate global, dentro do qual assume-se como maior relevância a necessidade de se satisfazer as necessidades humanas básicas. Jamali (2006) complementa a definição de Dyllick e Hockerts (2002) ao admitir que a sustentabilidade organizacional, em âmbito macro, é compreendida como uma série de políticas, interligadas às atividades organizacionais e aos processos de tomadas de decisões, que objetivam garantir que as empresas venham a maximizar os impactos positivos de suas atividades em relação à sociedade ou, ainda, que elas operem por métodos que vislumbrem a necessidade de se encontrar ou exceder as expectativas éticas, legais, comerciais e públicas que as sociedades possuem em relação às organizações.

A realização da sustentabilidade organizacional, portanto, não é uma tarefa trivial, mas sim um propósito acompanhado por uma série de desafios. Um desses desafios é extrair a noção de que todos os pilares da sustentabilidade são iguais em termos de relevância, e também acabar com a tentativa de traduzir todos os benefícios da sustentabilidade em mensurações financeiras. Não é sempre fácil ou possível quantificar diretamente os benefícios financeiros da sustentabilidade organizacional; e, frequentemente, mesmo sendo eles óbvios, possuem um tempo de retorno maior do que os usuais. Essa situação leva à necessidade de se alcançar um desenvolvimento paradigmático sobre a maneira pela qual os negócios são conduzidos (AZAPAGIC, 2003).

Por meio das considerações apresentadas, faz-se necessário compor uma definição da sustentabilidade organizacional coerente com os propósitos deste artigo. Propõe-se que a sustentabilidade organizacional é meta componente da responsabilidade das organizações alcançarem o desenvolvimento sustentável. Ela é dual, uma vez que precisa ser crítica em termos teóricos e funcionalista em termos práticos. Assume uma identidade multifacetada, pois é positiva, por se preocupar com as análises científicas e os choques filosóficos entre economia e ecologia, e também normativa, por estar interessada nos acordos e propostas direta e indiretamente relacionados às organizações e que contemplem em seus discursos considerações sobre o desenvolvimento sustentável. Ela procura o equilíbrio de cada sistema de ação organizacional, a fim de que esses equilíbrios sejam somados e interagidos em prol de um balanceado desenvolvimento sustentável. Trata-se de uma vertente dos estudos da sustentabilidade inserida na escola holística, por compreender a relevância da interação entre as partes e o todo, e desse todo com o ambiente. Ela confere às organizações e ao meio a possibilidade de continuidade ecossistêmica por inovações incrementais e radicais, mas com a preocupação de validar o conjunto de interesses estabelecidos pelos indivíduos e pelas organizações, em preocupações que enriqueçam os princípios sustentáveis da organização. A sustentabilidade organizacional, portanto, não é estável, mas sim dinâmica e cíclica, uma vez que se renova, ininterruptamente, a fim de que sua meta maior, um desenvolvimento sustentável, possa ser alcançada.

Trata-se da proposição de um conceito amplo e abrangente. No entanto, essa amplitude não significa que o conceito apresentado tente representar uma meta, perspectiva da sustentabilidade organizacional, que traga consigo contribuições desconexas de todas as vertentes analíticas estudadas, mas, ao invés disso, a construção da definição proposta procura adotar uma análise mais compreensiva e integrativa sobre o que realmente constitui e alicerça a sustentabilidade das organizações.

\section{Considerações finais: hierarquizando os caminhos estratégicos para o desenvolvimento sustentável}

O presente artigo foi realizado com o objetivo de hierarquizar teoricamente, junto às discussões vinculadas à responsabilidade social empresarial e à sustentabilidade organizacional, caminhos estratégicos para o desenvolvimento sustentável. Para tanto foi 
realizada uma pesquisa básica, qualitativa, exploratória e bibliográfica. A constituição do referencial teórico envolveu contribuições oriundas de autores que tratam de estratégias organizacionais e da visão baseada em recursos, da responsabilidade social empresarial, da diferença entre desenvolvimento sustentável e sustentabilidade, das vertentes analíticas da sustentabilidade e da sustentabilidade organizacional.

O raciocínio que guiou a elaboração deste estudo considerou a responsabilidade social empresarial e a sustentabilidade organizacional como dois caminhos estratégicos possíveis de serem adotados pelas organizações em prol de ofertarem contribuições para o alcance de um desenvolvimento sustentável. Ao tomar como base o referencial teórico desenvolvido esclarece-se que esses caminhos estratégicos são desenvolvidos nos ambientes internos das organizações, pela observância de inúmeras externalidades e pela ponderação de recursos e capacidades internas que permitam o enfrentamento de tais problemáticas por mecanismos de gestão coerentes para com a dimensão do objetivo almejado, ou seja, o desenvolvimento sustentável.

Embora parecidas faz-se necessária a admoestação de que responsabilidade social e sustentabilidade organizacional diferem, ainda que ambas possam ser admitidas como caminhos estratégicos formulados internamente às organizações. Em termos de complexidade indica-se que a responsabilidade social empresarial representa um dos passos iniciais a ser dado por uma empresa a fim de que sua respectiva sustentabilidade organizacional seja estabelecida. Propõe-se, assim, que a responsabilidade social empresarial constitui uma iniciativa estratégica que fundamenta a sustentabilidade organizacional, a qual é parte integrante e fenômeno consequente da estratégia organizacional responsável por conciliar interesses organizacionais, expectativas sociais e preservação ambiental, para que, assim, o objetivo estratégico maior, o desenvolvimento sustentável, seja garantido no que tange à responsabilidade organizacional de viabilizá-lo.

Admoesta-se, assim, que a sustentabilidade organizacional concede força estratégica aos princípios da responsabilidade social empresarial e respalda as decisões e os processos empresariais acatados rumo ao desenvolvimento sustentável com mecanismos de gestão coerentes para com as metas assumidas pela organização, a fim de que ela galgue representatividade em ações sociais mobilizadas em prol do desenvolvimento sustentável. Considera-se, então, que a maturidade e a ramificação da responsabilidade social empresarial pode ser observada na sustentabilidade organizacional, logo, aquela constitui em um caminho organizacional estratégico inicial e esta representa um caminho organizacional estratégico avançado para a viabilização do desenvolvimento sustentável. O Quadro 4 resume os principais temas abordados no artigo em conceitos relacionados às organizações.

\section{Fenômeno em análise Conceituação em relação às organizações}

Desenvolvimento sustentável

Sustentabilidade

Sustentabilidade organizacional
O desenvolvimento sustentável enquanto objetivo relaciona economia e ecologia; enquanto processo interliga ecologia e sociedade; e enquanto ação organizacional exige a vinculação entre economia, ecologia e sociedade. O desenvolvimento sustentável busca a soma dos equilíbrios dos sistemas sociais, econômicos e ambientais, e mais um equilíbrio maior composto por todas as interações entre esses sistemas.

A sustentabilidade compõe ações mais objetivas que propiciam o alcance de um desenvolvimento sustentável. Se considerada cada meta organizacional como um objetivo final em busca de um equilíbrio sistêmico, considera-se cada uma delas relacionadas à sustentabilidade. A soma de tais metas e a adição de sucesso desses objetivos sustentáveis é o que propicia um desenvolvimento sustentável.

Procura o equilíbrio de cada sistema de ação organizacional, a fim de que esses equilíbrios sejam somados e interagidos em prol de um balanceado desenvolvimento sustentável. Ela possui a responsabilidade de validar o conjunto de interesses estabelecidos pelos indivíduos e pelas organizações, em preocupações que enriqueçam os princípios sustentáveis da organização.

Quadro 4 - Definições e relações de dependências entre os fenômenos investigados

(Continua) 


\begin{tabular}{ll} 
Fenômeno em análise & Conceituação em relação às organizações \\
\hline $\begin{array}{l}\text { Responsabilidade social } \\
\text { empresarial }\end{array}$ & $\begin{array}{l}\text { A responsabilidade social empresarial trata de questões como transparência, diálogo com os } \\
\text { stakeholders e atos de reportar ações sustentáveis. Ela é compreendida como apenas um dos estágios } \\
\text { da sustentabilidade organizacional, no qual as empresas procuram meios que viabilizem práticas de } \\
\text { gestão que integrem as dimensões da sustentabilidade. }\end{array}$
\end{tabular}

Quadro 4 - Definições e relações de dependências entre os fenômenos investigados

(Conclusão) Fonte: Adaptado de DYLLICK; HOCKERTS, 2002; KAPTEIN; WEMP, 2002; LÉLÉ, 1991; OSORIO; LOBATO; CASTILLO, 2005; JIMÉNEZ HERRERO, 2000.

Por meio do quadro é possível compreender a seguinte lógica de expressão e acontecimento desses fenômenos junto a pesquisas relacionadas às organizações. A responsabilidade social empresarial constitui uma série de ações específicas que compõem apenas parte dos processos necessários para o alcance da sustentabilidade organizacional, que, por sua vez, estrutura-se por decisões interessadas em promover um equilíbrio de tudo o que se relaciona e é influenciado direta e indiretamente pelo agir operacional da organização. A sustentabilidade organizacional, portanto, é apenas uma das sustentabilidades necessárias para o alcance do desenvolvimento sustentável, logo, admite-se que cada uma dessas sustentabilidades é uma meta incumbida de alcançar esse fenômeno maior, o qual não é estanque, mas ininterrupto, uma vez que os sistemas transformam-se continuamente, bem por isso, não dispensa a atuação efetiva e responsável das organizações em causas sustentáveis.

Este artigo abre uma extensa agenda de pesquisa possível de ser explorada por pesquisadores que se interessem sobre os temas aqui abordados. Outros estudos podem ser desenvolvidos com o objetivo de identificar outros caminhos estratégicos organizacionais que contribuam para o alcance do desenvolvimento sustentável. Cabe também a realização de estudos empíricos que estejam interessados em verificar se tais caminhos estratégicos realmente estão auxiliando a moldar ou a impedir a configuração desse desenvolvimento sustentável.

\section{Referências}

AZAPAGIC, A. Systems approach to corporate sustainability: a general management framework. Institution of Chemical Engineers, New Jersey, v. 81, n. 5, p. 303-316, 2003.
AZAPAGIC, A.; PERDAN, S. Indicators of sustainable development for industry: a general framework. Trans IChemE, New Jersey, v. 78, n. 4, p. 243-261, 2000.

BARNEY,J. B. Firm resources and sustained competitive advantage. Journal of Management, New York, v. 17, n. 1, p. 99-121, 1991.

BOWMAN, C.; AMBROSINI, V. How the resource-based and the dynamic capability views of the firm inform corporate-level strategy. British Journal of Management, New York, v. 14, n. 2, p. 289-303, 2003.

CALDART, A. A.; RICART, J. E. Corporate strategy revisited: a view from complexity theory. European Management Review, London, v. 1, n. 1, p. 96-104, 2004.

CAMPANHOL, E. M.; BREDA, F. A. Responsabilidade social: entre o assistencialismo e a moderna gestão corporativa. In: ENCONTRO DA ASSOCIAÇÃO NACIONAL DE PÓS-GRADUAÇÃO E PESQUISA EM ADMINISTRAÇÃO, 29., 2005, Brasília. Anais... Rio de Janeiro: ANPAD, 2005. p. 1-12.

CLARK, W. C. Managing Planet Earth. Scientific American, New York, v. 261, n. 3, p. 47-54, 1989.

CLARKE, J. J. Nature in question. 2nd ed. London: Earthscan Publications, 1993.

DALY, H. E. Allocation, distribution and scale: towards an economics that is efficient, just and sustainable. Ecological Economics, New York, v. 6, n. 3, p. 185194, 1992.

DYLLICK, T.; HOCKERTS, K. Beyond the business case for corporate sustainability. Business Strategy and the Environment, New York, v. 11, n. 2, p. 130$141,2002$. 
EGRI, C.P.; PINFIELD, L. T. As organizações e a biosfera: ecologia e meio ambiente. In: CLEGG, S. R.; HARDY, C.; NORD, W. R. Handbook de estudos organizacionais: modelos de análise e novas questões em estudos organizacionais. 2. ed. São Paulo: Atlas, 2007. p. 361-197.

FERGUS, A. H. T.; ROWNEY, J. I. A. Sustainable development: lost meaning and opportunity? Journal of Business Ethics, New York, v. 60, n. 1, p. 17-27, 2005.

FREEMAN, R. E. Strategic management: a stakeholder approach. 2nd ed. Marshfield: Pitman Publishing Inc., 1984.

FREILING, J.; GERSCH, M.; GOEKE, C. On the path towards a competence-based theory of the firm. Organization Studies, v. 29, n. 8/9, p. 1143-1164, 2008.

FRIEDMAN, M. Capitalism and freedom. 2nd ed. Chicago: University of Chicago Press, 1962.

GLADWIN, T. N.; KENNELLY, J. J.; KRAUSE, T. S. Shifting paradigms for sustainable development: implications for management theory and research. Academy of Management, New York, v. 20, n. 4, p. 874-907, 1995.

GÖBBELS, M. Reframing corporate social responsibility: the contemporary conception of a fuzzy notion. Journal of Business Ethics, New York, v. 44, p. 95-105, 2002.

GOOLD, M.; CAMPBELL, A.; ALEXANDER, M. Corporate strategy and parenting theory. Long Range Planning, New York, v. 31, n. 2, p. 308-314, 1998.

GORE, A. Earth in balance: ecology and the human spirit. 2nd ed. New York: Houghton Miffin, 1992.

HARDJONO, T. W.; van MARREWIJK, M. The social dimensions of business excellence. Corporate Environmental Strategy, New York, v. 8, n. 3, p. 223-233, 2001.

HART, S. A natural-resource-based view of the firm. Academy of Management Review, New York, v. 20, n. 4, p. 986-1014, 1995.

HENDERSON, D. Misguided virtue, false notions of corporate social responsibility. 2nd ed. New Zealand: Business Round Table, 2001.

JAMALI, D. Insights into the triple bottom line integration from a learning organization perspective. Business Process Management Journal, New York, v. 12, n. 6, p. 809-821, 2006.

JIMÉNEZ HERRERO, L. M. Desarrollo sostenible: transición hacia la coevolución global. 2. ed. Madrid: Pirámide, 2000.
KAPTEIN, M; WEMPE, J. The balanced company: a theory of corporate integrity. 2nd ed. Oxford: Oxford University Press, 2002.

LEE, K. N. Greed, scale mismatch and learning. Ecological Applications, New York, v. 3, n. 4, p. 560-564, 1993.

LEFF, K. M. Greed, scale mismatch and learning. Ecological Applications, New York, v. 3, n. 4, p. 560-564, 1993.

LÉLÉ, S. M. Sustainable development: a critical review. World Development, New York, v. 19, n. 6, p. 607-621, 1991.

MARKIDES, C.; WILLIAMSON, P. Related Diversification, core competences and corporate performance. Strategic Management Journal, New York, v. 15, n. 5, p. 149-165, 1994.

MARTINS, G. A.; THEÓPHILO, C. R. Metodologia da investigação científica para ciências sociais aplicadas. 2. ed. São Paulo: Atlas, 2007.

MCINTONSH, M. et al. Cidadania vorporativa: estratégias bem-sucedidas para empresas responsáveis. 2. ed. São Paulo: Qualitymark, 2001.

MEBRATU, D. Sustainability and sustainable development: historical and conceptual review. Environment Impact Assessment Review, New York, v. 18, p. 493520, 1998.

MEBRATU, D. Sustainability as a scientific paradigm. Lund: International Institute for Environmental Economics, 1996.

MERRY, U. Organizational strategy on different landscapes: a new science approach. Systemic Pratctice and Action Research, New York, v. 12, n. 3, p. 257-278, 1999.

MILNE, M. J.; KEARINS, K.; WALTON, S. Creating adventures in wonderland: the journey metaphor and environmental sustainability. Organization, New York, v. 13 , n. 6 , p. $801-839,2006$.

OSORIO, L. A. R.; LOBATO, M. O.; CASTILLO, X. A. Debates on sustainable development: towards a holistic view of reality. Environment, Development and Sustainability, New York, v. 7, p. 501-518, 2005.

PENROSE, E. T. The theory of the growth of the firm. 2nd ed. New York: Wiley, 1959.

PORTER, M. Estratégia competitiva. 2. ed. Rio de Janeiro: Campus, 1991. 
PORTER, M.; van der LINDE, C. Green and competitive: ending the stalemate. Harvard Business Review, New York, v. 73, n. 5, p.120-129, 1995.

QUAZI, A.M.; O'BRIEN, D. An empirical test of a cross-national model of corporate social responsibility. Journal of Business Ethics, New York, v. 25, n. 3, p. 33-51, 2000.

ROBINSON, S. Key survival issues: practical steps toward corporate environmental sustainability. Corporate Environmental Strategy, New York, v. 7, n. 1, p. 92-105, 2000.

ROLSTON, H. Conserving natural value. 2nd ed. New York: Columbia University Press, 1994.

ROULAC, S. E. Corporate strategy is integral do corporate business strategy. Journal of Real Estate Research, New York, v. 22, n. 1/2, p. 129-152, 2001.

RUGMAN, A. M.; VERBEKE, A. Corporate strategies and environmental regulations: an organization framework. Strategic Management Journal, New York, v. 19, n. 8, p. 363-375, 1998.

SAVITZ, A. W.; WEBER, K. The triple bottom line: how today's best-run companies are achieving economic, social, and environmental success - and how you can too. 2nd ed. San Francisco: Jossey-Bass, 2006.

TAYLOR, D. E. The rise of the environmental justice paradigm: injustice framing and the social construction of the environment discourses. American Behavioral Scientist, New York, v. 43, n. 4, p. 508-580, 2000.

van MARREWIJK, M. Concepts and definitions of CSR and corporate sustainability: between agency and communion. Journal of Business Ethics, New York, v. 44, p. 95-105, 2003a.

van MARREWIJK, M.; WERRE, M. Multiple levels of corporate sustainability. Journal of Business Ethics, New York, v. 44, p. 107-119, 2003 b.

VIEDERMAN, S. The economics of sustainability: challenges. Recife: Fundação Joaquim Nabuco, 1994. Paper presented at the workshop, The Economics of Sustainability.

WACKERNAGEL, M.; REES, W. Our ecological footprint: reducing human impact on earth. 2nd ed. Philadelphia: New Society Publishers, 1996.

WERNEFELT, B. A resource-based view of the firm. Strategic Management Journal, New York, v. 5, n. 2, p. 171-180, 1984.
WRIGHT, P. M.; DUNFORD, B. B.; SNELL, S. A. Human resources and the resource based view of the firm. Journal of Management, New York, v. 27, n. 12, p. 701-721, 2001.

WORLD COMISSION ON ENVIRONMENT AND DEVELOPMENT (WCED). Our common future the Brundtland report). Oxford: Oxford University Press, 1987.

Recebido: 30/08/2010

Received: 08/30/2010

Aprovado: $16 / 11 / 2010$

Approved: 11/16/2010 